\title{
A GAMMA-RAY IONIZATION CHAMBER FOR USE WITH A DIRECT CURRENT AMPLIFIER
}

\author{
By L. F. Curtiss
}

\section{ABSTRACT}

A description is given of a new type of gamma-ray ionization chamber in which the source is within the central electrode. The chamber is so designed with guard rings that only an annular zone of ionization about the source of gamma rays contributes to the measured ionization current. This arrangment yields ionization currents for average preparations of radium of the order of 10-11 amperes. These currents are readily amplified by a vacuum-tube amplifier so as to be readable on a microammeter. This arrangement has been tested in the Radium Laboratory at the Bureau of Standards and found to give results accurately comparable with the determinations made by means of a gold-leaf electroscope. It possesses the advantages over the electroscope that it is more rugged, more easily read, no blank drift need be taken, and the operator may be at a distance from the gamma-ray source during readings. In addition, the source is entirely screened by lead when in position for measurement, and sources of all strengths are measured in the same position. The arrangement is particularly suited to the routine standardization of commercial preparations of radium and radon.

\section{TABLE OF CONTENTS}

I. Introduction _.

II. Geometrical arrangement of the ionization chamber

III. Precision of method.

\section{INTRODUCTION}

In making gamma-ray comparisons of preparations of radium or radon it is desirable to reduce as far as possible the exposure of the observer to the radiation. This is of greatest importance where large quantities of radium are to be handled. It requires that observations be made as quickly as possible and that the radium should be at a considerable distance from the observer at all times. Many of the devices in general use are far from satisfactory in these respects. As is well known, the inverse square law is the most important factor in reducing exposure to gamma radiation. In devising any new method of measurement, therefore, first consideration should be given to increasing the distance between the preparation and the observer when taking readings. In the case of the gold-leaf electroscope this can only be accomplished by optical means. ${ }^{1}$ Consequently the distance at which the observer can conveniently observe the motion of the gold leaf is limited. Furthermore, exposure to radiation cannot be reduced by screening with this method of measurement.

1 Curtiss, L. F., Jour. Opt. Soc. Amer. and Rev. Sci. Insts., vol. 16, p. 363, 1928. 
This paper describes a new type of ionization chamber which, when used with a simple direct-current vacuum-tube amplifier, provides a means of comparing radium preparations and other gamma-ray sources. This method provides greater protection for the operator and reduces the time and labor required for making accurate comparisons.

\section{GEOMETRICAL ARRANGEMENT OF THE IONIZATION CHAMBER}

When replacing the gold-leaf electroscope by an ionization chamber for use with a vacuum-tube circuit, a considerable simplification of

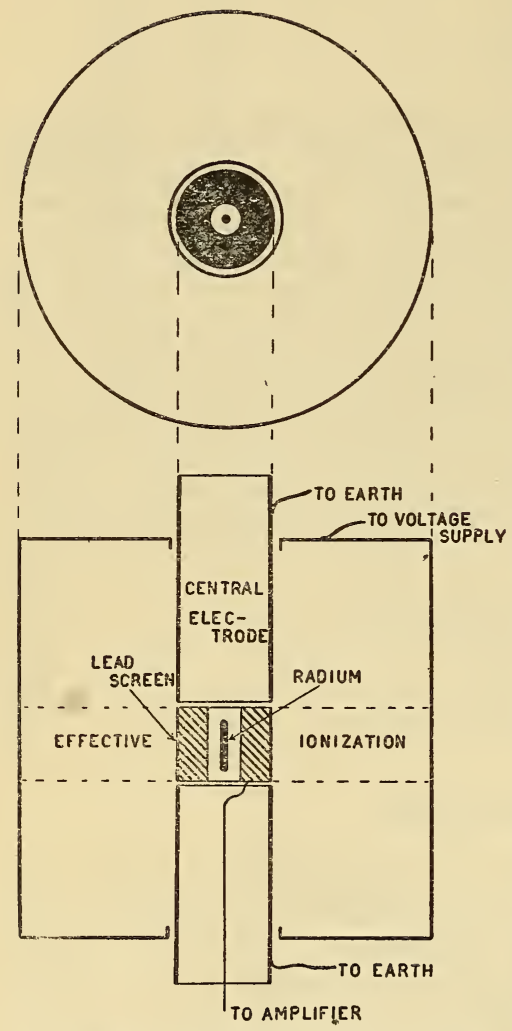

Figure 1.-Diagram of new type of ionization chamber.

the problem is achieved if a form of chamber is used which yields as large an ionization current as possible for a given preparation. The usual electroscope or ionization chamber utilizes only a small fraction of the total ionization. The maximum current would be obtained by placing the gamma-ray source inside a small spherical electrode at the center of a large hollow sphere. An approximation to this arrangement can be obtained by placing the source in a cylindrical electrode, located on the axis of a cylindrical ionization chamber. This form is easy to construct and yields an ionization current sufficiently larger to be readily amplified and measured.

In designing such a chamber precautions must be taken to avoid an arrangement which will cause the corrections for absorption of radiation in the walls of metal containers to vary erratically. The ideal condition would result in these corrections becoming indentical with those determined by use of a gold-leaf electroscope when the preparation is at some distance from the electroscope. It requires that all radiation which does not proceed nearly normal to the axis of the radium needle or tube should be prevented from contributing to the ionization current which is measured. It was found that this requirement is sufficiently satisfied if the ionization included in an annular space (about the preparation) of a height approximately equal to the length of the preparation and an external diameter at least 10 times this length is allowed to contribute to the measured current. The selected arrangement is indicated in the diagram in figure 1. The central cylindrical electrode is composed of 3 sections, the intermediate of which is electrically insulated and provided with a lead connecting it with a device for measuring the current flowing to it. 
This insulated section, in the center of which the radium preparation is placed, has thick lead walls to provide proper filtering of the gamma radiation. The upper and lower sections are connected to earth; consequently the ionization current collected by them does not contribute to the measured current. Since the intermediate section never rises more than 1 or 2 hundredths of a volt above earth potential and the difference of potential between the central electrode and outer walls of the chamber is several hundred volts, the electro-static field is practically radial and uniform over the surface of the intermediate section; consequently, the volume of effective ionization is approximately that indicated.

A scale drawing of the vertical section of a chamber constructed according to this design is shown in figure 2. The horizontal sections of all parts are circular. The central electrode made up of three parts, E, C, and $\mathrm{D}$, is assembled into a single rigid unit by means of hard-rubber bushings pressed into the brass sheath of the upper and lower section. The intermediate, insulated section, C, has lead walls 1 centimeter thick. The radium preparation, $R$, is introduced through the opening at $\mathrm{A}$ and held in position on the axis of the electrode by an aluminum holder, not shown. To make possible a fairly deep well in the leadwalled section and thus provide for better shielding of the

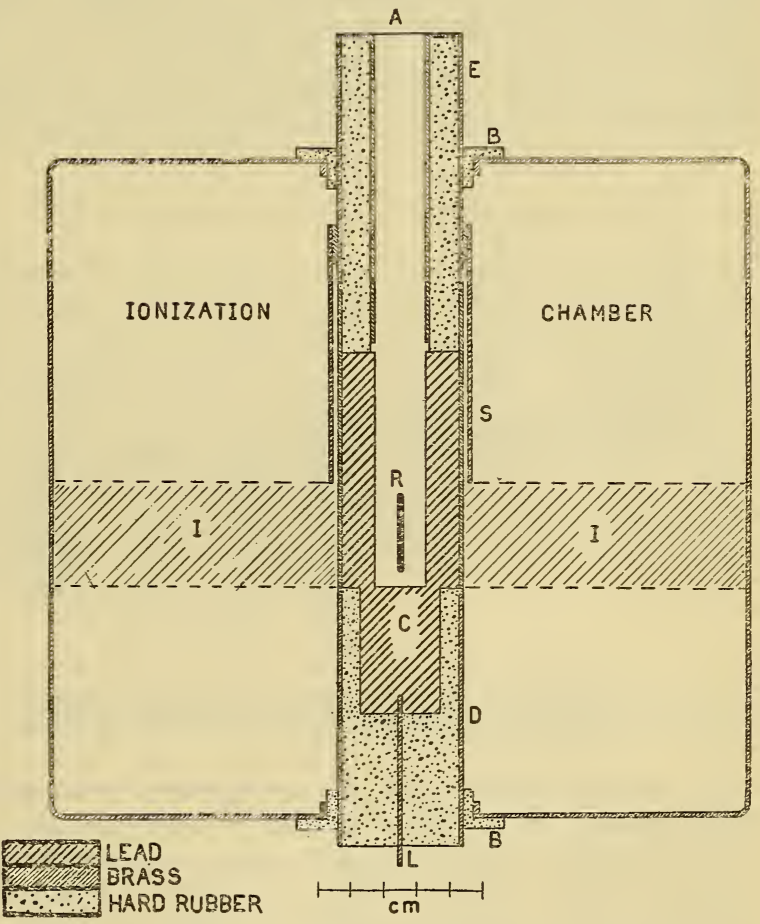

Frgure 2.-Vertical cross section of actual chamber. upper parts of the chamber from softer radiation, this section is made about twice as long as the average radium preparation; but the effective length of the section is limited by the tubular-brass screen, S, attached to the upper section. The annular zone, I, then becomes the volume of effective ionization. Connection to the current-measuring device is made by means of the lead, L, brought out through the center of the hard-rubber bushing in the lower section of the central electrode. The brass outer walls of the ionization chamber are supported by the hard-rubber collars, BB. 
The use of an arrangement which yields comparatively large ionization currents eliminates many of the problems often met with in constructing ionization chambers. Insulation of moderate quality is sufficient since small leaks will be an extremely small percentage of the total current. Extreme care in cleaning the inner surface of the chamber is not necessary since the usual small radioactive contamination on metals is negligible. In addition all trouble from increased conductivity of insulators, as reported by Guében ${ }^{2}$ when exposed to strong gamma radiation is eliminated since these variations are also insignificant in comparison with the main ionization current.

The complete arrangement is indicated in the diagram shown in figure 3 . In this, the ionization chamber, $\mathrm{C}$, is supplied with a voltage sufficient to produce saturation by the battery, ${ }^{3} \mathrm{~B}$. The insulated section of the central electrode is connected by a long paraffin-filled tube, with wire along its axis, to a 2-stage vacuum-tube amplifier described elsewhere. ${ }^{4}$ The resistance, $R$, may conveniently be $10^{8}$ ohms. The only other significant change in the amplifier from that described in the reference, is the introduction of a potentiometer, $\mathrm{P}$,

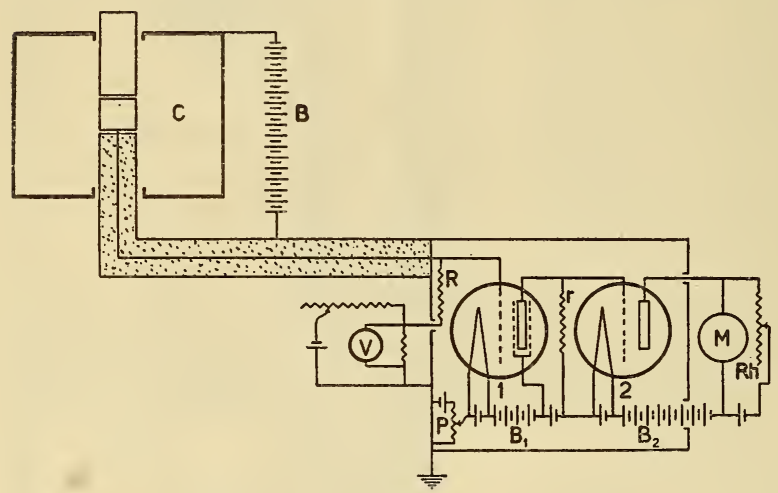

FiguRe 3.-Diagram showing complete assembly for making gamma-ray comparisons of radioactive preparations. and a provision for compens ating the $I R$ drop in the resistance, $R$, so that a null method may be used, the microammeter, $M$, serving only to indicate the balancing of the drop in $R$. The method of use is made clear by a description of the procedure in making a measurement. With no radium in the chamber and the millivol tmeter reading 0 , the microammeter, $M$, is adjusted to an arbitrary 0 by means of the rheostat, Rh. The radium is now put in the chamber and the microammeter, $\mathrm{M}$, is brought back to the selected 0 by adjusting the reading of the millivoltmeter, $\mathrm{V}$, until this is accomplished. The change in the potential difference across $\mathrm{R}$ produced by the ionization current resulting from introduction of the radium into the chamber is directly proportional to the reading of the millivoltmeter, $\mathrm{V}$. This procedure permits all readings to be taken at this same value of the control grid potential of the first tube and thereby eliminates errors which would arise from changes in the control grid current when using the deflections of the microammeter, $M$, to measure the ionization current. The potentiometer, $\mathrm{P}$, is used to provide a control grid bias such that the first tube operates on linear portion of its

\footnotetext{
2 Guében, G., Ann. Soc. Sci. de Bruxelles, vol. 49, p. 12, 1929.

3 This voltage was obtained by a transformer and rectifier with simple filter circuit from the alternatingcurrent supply. Live voltage fluctuations caused no detectable fluctuation of meters in output circuit of the amplifier.

1 Curtiss, L. F., B.S. Jour. Research, vol. 10, (RP550) p. 583, 1933.
} 
characteristic curve and is not changed once the desired point has been found. When a new tube is put in the circuit, it is usually necessary to redetermine the correct bias. The writer has found that a great deal of the annoying fluctuations frequently encountered when using ordinary radio tubes in a circuit as described above, arise in the molded base of the tube and that even when using a tube with control grid brought out of the top it is quite essential to remove the base for steady operation. Considerable improvement of behavior is also obtained by painting the outside of the tube to within several millimeters of the portions where leads are brought through the glass with a conducting paint. This coating is grounded. "Spray tubes" might serve equally well.

A factor which contributes to the speed and accuracy of this method is that all preparations, regardless of strength, are measured in the same position. This is of importance where many preparations of widely different radium content are being measured. Errors and delays arising from adjusting a radium holder to the proper distance from the electroscope are eliminated.

\section{PRECISION OF METHOD}

Since this arrangement is intended to take the place of a gold-leaf electroscope in standardizing radium preparations by the gamma-ray method, it is desirable to submit some evidence regarding its precision and reliability in comparison with the electroscope. This can be done most conveniently by table 1 which shows the results obtained from all readings taken on a set of 5 radium preparations contained in platinum tubes with walls 0.3 millimeters thick using the same radium standard, sealed in glass, for reference. These results are typical of a large number of comparisons which have been made between the two methods.

TABLE 1

\begin{tabular}{|c|c|c|c|c|c|c|}
\hline \multicolumn{2}{|c|}{ Electroscope } & $\begin{array}{l}\text { Ionization } \\
\text { chamber }\end{array}$ & $\begin{array}{l}\text { Electro- } \\
\text { scope }\end{array}$ & $\begin{array}{l}\text { Ionization } \\
\text { chamber }\end{array}$ & $\begin{array}{l}\text { Electro- } \\
\text { scope }\end{array}$ & $\begin{array}{l}\text { Ionization } \\
\text { chamber }\end{array}$ \\
\hline \multicolumn{3}{|c|}{ Preparation no. 20728} & \multicolumn{2}{|c|}{ Preparation no. 20730} & \multicolumn{2}{|c|}{ Preparation no. 20732} \\
\hline & $\begin{array}{r}10.00 \\
9.90 \\
9.95 \\
9.80 \\
9.90 \\
9.80\end{array}$ & $\begin{array}{l}9.87 \\
9.88 \\
9.88 \\
9.87 \\
9.89 \\
9.87\end{array}$ & $\begin{array}{l}9.70 \\
9.75 \\
9.70 \\
9.70 \\
9.75 \\
9.70\end{array}$ & $\begin{array}{l}9.75 \\
9.64 \\
9.65 \\
9.67 \\
9.67 \\
9.70\end{array}$ & $\begin{array}{r}10.00 \\
9.95 \\
9.95 \\
9.95 \\
9.86 \\
9.90\end{array}$ & $\begin{array}{l}9.86 \\
9.86 \\
9.86 \\
9.86 \\
9.86 \\
9.89\end{array}$ \\
\hline $\begin{array}{l}\text { Average } \\
\text { Probable } \\
\text { error }\end{array}$ & $\begin{array}{l}9.89 \\
+.022\end{array}$ & $\begin{array}{l}9.88 \\
\pm .002\end{array}$ & $\begin{array}{l}9.72 \\
+.007\end{array}$ & $\begin{array}{l}9.68 \\
\pm .008\end{array}$ & $\begin{array}{l}9.93 \\
\pm .013\end{array}$ & $\begin{array}{r}9.86 \\
\pm .004\end{array}$ \\
\hline \multicolumn{3}{|c|}{ Preparation no. 20729} & \multicolumn{2}{|c|}{ Preparation no. 20731} & \multicolumn{2}{|c|}{ Preparation no. 20733} \\
\hline & $\begin{array}{l}9.56 \\
9.70 \\
9.66 \\
9.60 \\
9.51 \\
9.46\end{array}$ & $\begin{array}{l}9.52 \\
9.52 \\
9.52 \\
9.51 \\
9.54 \\
9.52\end{array}$ & $\begin{array}{r}10.05 \\
9.90 \\
9.95 \\
9.86 \\
9.80 \\
9.80\end{array}$ & $\begin{array}{l}9.86 \\
9.90 \\
9.89 \\
9.88 \\
9.89 \\
9.89\end{array}$ & $\begin{array}{r}10.04 \\
10.10 \\
9.99 \\
9.99 \\
9.94 \\
9.94\end{array}$ & $\begin{array}{r}10.01 \\
10.01 \\
9.99 \\
10.01 \\
9.99 \\
9.99\end{array}$ \\
\hline $\begin{array}{l}\text { Average } \\
\text { Probable } \\
\text { error }\end{array}$ & $\begin{array}{r}9.58 \\
\pm .024\end{array}$ & $\begin{array}{l}9.52 \\
\pm .002\end{array}$ & $\begin{array}{r}9.89 \\
\pm .024\end{array}$ & $\begin{array}{c}9.88 \\
\pm .004\end{array}$ & $\begin{array}{l}10.00 \\
\pm .017\end{array}$ & $\begin{array}{l}10.00 \\
\pm .002\end{array}$ \\
\hline
\end{tabular}


From a study of the above table, it is evident that the systematic errors between the two instruments do not lie outside the accuracy usually claimed in the measurement of commercial radium preparations, that is, 0.7 percent. From the probable errors computed for each set of observations, it is also clear that the accuracy of the individual readings with the ionization chamber considerably exceeds that of those made with the electroscope. This increased accuracy can be used to reduce the number of observations required to obtain measurements of the required precision, and it has been found that three readings with the ionization chamber give results comparable in accuracy with those obtained from 18 individual readings on the electroscope.

The results given in the table also serve to show that the absorption correction for the ionization chamber is the same as for the electroscope. Any difference would appear as a systematic deviation in the results obtained by the two methods. Numerous measurements on a variety of types of preparations have failed to show any such deviation.

Since fewer readings are required to obtain results of the same accuracy, measurements can be made with the ionization chamber in about one tenth the time required with the electroscope. Furthermore, the reduction of readings to milligrams of radium is less laborious than for the electroscope since the readings of the millivoltmeter are directly proportional to gamma radiation of the preparations. The natural ionization is compensated in the zero setting of the microammeter. Thus the total saving of time afforded by the ionization chamber method is considerable.

The writer wishes to acknowledge the cooperation of G. W. Gardiner who suggested the design of chamber described, and of A. V. Astin, for help in eliminating some of the difficulties encountered. $\mathrm{He}$ is also pleased to acknowledge the help of L. L. Stockmann and B. W. Brown in constructing the parts of the chamber and amplifier.

Washington, October 25, 1933. 